\title{
Challenges and perspectives of regional cooperation within COOMET - The Euro-Asian Regional Metrology Organization
}

\author{
Pavel Neyezhmakov ${ }^{1}$, Klaus-Dieter Sommer ${ }^{2}$ \\ ${ }^{1}$ National Scientific Centre "Institute of Metrology", Mironositskaya 42, 61002 Kharkov, Ukraine \\ ${ }^{2}$ Physikalisch-Technische Bundesanstalt, Bundesallee 100, 38116 Braunschweig, Germany
}

\begin{abstract}
The creation of the metrological infrastructure providing traceable results of the measurement is one of the major tasks of COOMET member-countries from Central Asia and to Caucasian Region. COOMET successfully cooperates in developing the basic metrology infrastructures of these countries. In accordance with strategic aims COOMET also supports metrological knowledge transfer and developing technical competence for innovations and scientific research. For the purpose of implementing joint research projects a TC 5 was established. Cooperation within TC 5 aims at activating the NMIs of COOMET member countries in the global integration process in science, technology and high-end manufacturing.
\end{abstract}

\section{Section: TECHNICAL NOTE}

Keywords: Metre Convention; RMO; JCRB; CIPM MRA; quality management system

Citation: Pavel Neyezhmakov, Klaus-Dieter Sommer, Challenges and perspectives of regional cooperation within COOMET - The Euro-Asian Regional Metrology Organization, Acta IMEKO, vol. 2, no. 2, article 16, December 2013, identifier: IMEKO-ACTA-02 (2013)-02-16

Editor: Paolo Carbone, University of Perugia

Received April 17 ${ }^{\text {th }}, 2013$; In final form December $14^{\text {th }}, 2013$; Published December 2013

Copyright: (C) 2013 IMEKO. This is an open-access article distributed under the terms of the Creative Commons Attribution 3.0 License, which permits unrestricted use, distribution, and reproduction in any medium, provided the original author and source are credited

Corresponding author: Pavel Neyezhmakov, email: pavel.neyezhmakov@rambler.ru

\section{INTRODUCTION}

COOMET (COOMET - abridged form from "COOperation in METrology") is a Regional Metrology Organization (RMO) [1] that establishes cooperation between the national metrology institutions of the countries of Central and Eastern Europe. It was founded in June 1991 and renamed Euro-Asian Cooperation of National Metrology Institutions in 2000. COOMET is open to any metrology institution from other regions; they can join as Associate Members. The basic activity of COOMET is cooperation in the following areas: measurement standards of physical quantities, legal metrology, quality management systems (QMS), information and training. The participation in COOMET activities gives an opportunity for the member countries to solve metrological tasks in a more efficient way on the basis of approved rules and procedures.

The current 15 members of COOMET are the metrology institutions from Armenia, Azerbaijan, Belarus, Bulgaria, Georgia, Kazakhstan, Kyrgyzstan, Lithuania, Moldova, Russia, Romania, Slovakia, Tajikistan, Ukraine and Uzbekistan. In addition, there are 3 Associate Members: Germany, DPR of Korea, and Cuba.
The objectives of COOMET are the following:

- Provide assistance in effectively addressing any problems relating to the uniformity of measures, uniformity of measurements and the required accuracy of their results;

- Provide assistance in promoting cooperation between national economies and eliminating technical barriers for international trade;

- Harmonize activities of metrology services of the Euro-Asian countries with similar activities in other regions.

- These objectives are accomplished by cooperation between interested COOMET Member Countries with regards to supporting activities related to the accreditation of national metrology institutes (NMIs), as well as calibration and measurement laboratories.

- At today's stage of progress, the tasks of COOMET are aimed at strengthening the links between the NMIs in order to solve common problems and to create effective mechanisms that will meet the following objectives: 


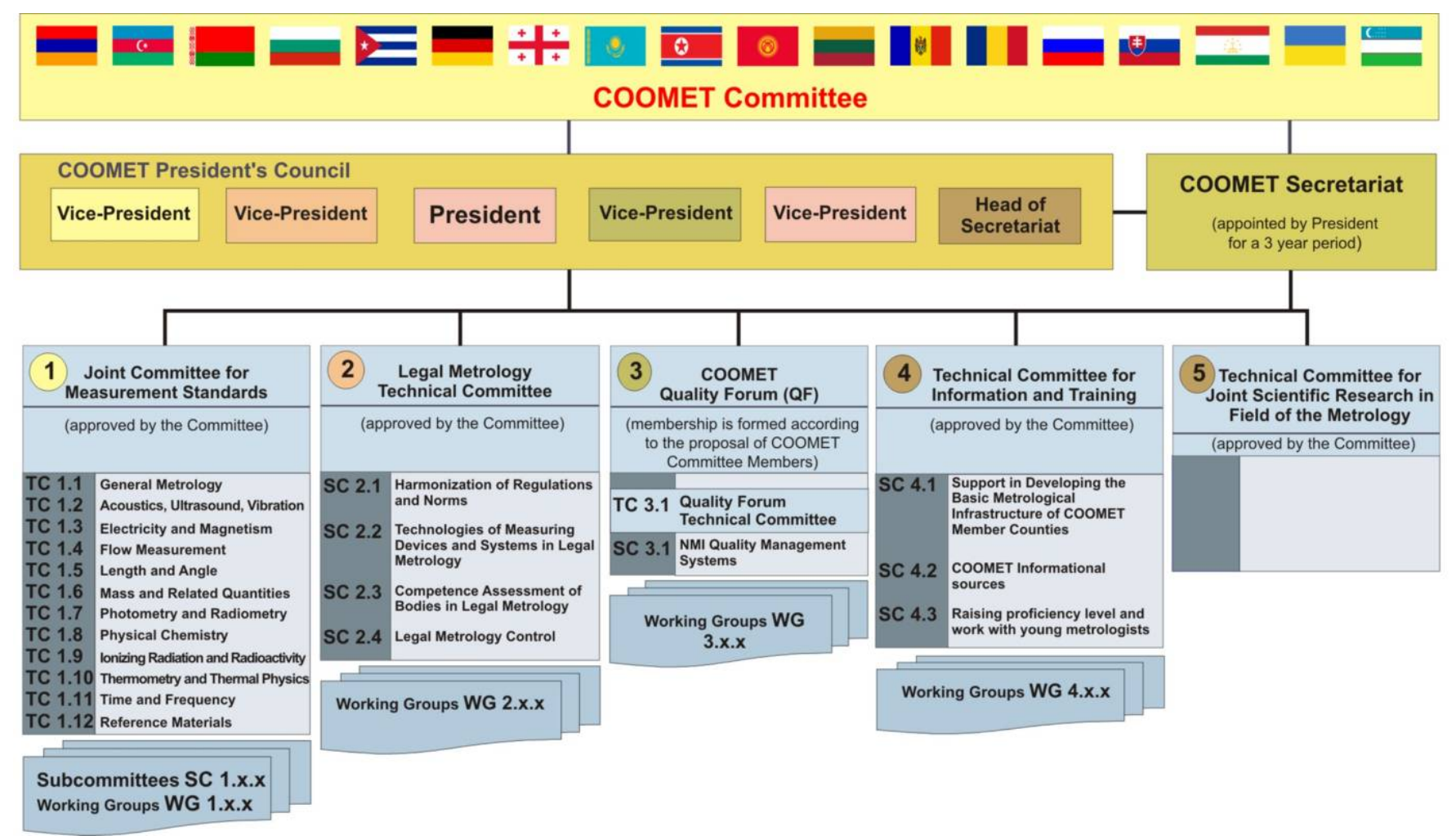

Figure 1. Current organizational structure of COOMET.

- Achieve compatibility of measurement standards and harmonize the requirements imposed on measuring instruments and methods for their metrological control;

- Recognize the equivalence of national certificates authenticating the results of metrology activities;

- Exchange information on the current status of National Metrology Services and their development;

- Collaborate in developing metrology projects; and

- Promote the exchange of metrology services.

A considerable advance in the formation of the current aims and tasks of the organization occurred as a result of several COOMET Committee meetings. At these meetings, decisions were made to increase the effectiveness of COOMET activities. It meant that planning of cooperation and informing about activities, interaction with other international and regional metrology organizations, etc. should be improved. According to the COOMET first Development Program for 2001-2002 there was developed and approved the organizational structure of COOMET, according to which structural and working bodies in all fields of cooperation covered by the MoU were created (see Figure 1). This structure provided wide involvement of qualified specialists of NMIs of Member Countries into COOMET activities.

Transformations directed toward the improvement of organization activities were reflected in the MoU and Rules of Procedure of COOMET, developed and fixed in the appropriate Documents. In 2005 the $\mathrm{MoU}$ and Rules of Procedure were amended with respect to the election of the COOMET President, according to which in the year before the end of the acting President's term, the future President is elected and authorized for the next 3 years.
One more important branch of COOMET activity is the development and adoption of the Conception of COOMET in 2005. Conception of Cooperation and Activity of COOMET determines the strategy tasks from a mediumterm and long-term perspective and provides for their implementation.

Among these tasks are the following:

- Strengthening innovation and technology components of Member Countries in the global system of economic and society development;

- Competent and economically effective participation of COOMET Member Countries in global integration processes in the fields of science, technology, science intensive production and the economy in general;

- Increasing the level of competitiveness of Member Countries in the fields of science and technology through participation in the world market of intellectual products, science intensive products and services.

\section{IMPLEMENTATION OF THE CIPM MRA}

The implementation of the CIPM MRA [2] is directed at the fulfillment of the following tasks:

- Organization and holding of regional comparison of measurement standards of COOMET Member Countries in order to assure the traceability of measurement standards to reference values of the SI units;

- Determination of the degree of equivalence of national measurement standards;

- Regional and interregional reviews of the calibration and measurement capabilities (CMC) and their 
publication in the BIPM Key Comparison Database (KCDB); and

- Evaluation of the Quality Management Systems (QMS) of NMIs through external review of each QMS.

Today, NMIs from 12 COOMET Member Countries are participants in the CIPM MRA. Six countries among them are members of the International Bureau of Weights and Measures (BIPM) and six are Associates of the General Conference on Weights and Measures (CGPM).

With the aim of providing support for NMIs in COOMET for the CIPM MRA purpose, several Recommendations have been successfully developed and approved.

According to the CIPM MRA D-04 "Calibration and Measurement Capabilities in the context of the CIPM MRA," [3] the Joint Committee of Regional Metrology Organizations and BIPM (JCRB) requires that $\mathrm{CMC}$ data presented for publication in Annex $\mathrm{C}$ should be completely supported by an implemented Quality System, controlled and approved by the local RMO, and the range and uncertainty of the CMC shouldn't contradict the information obtained from the results of key and supplementary comparisons. For the implementation of this JCRB requirement, COOMET has instituted the Program of Comparisons (Document COOMET D9). The Joint Committee for Measurement Standards (JCMS) annually updates the Program of Comparisons and presents the results at the President's Council meeting for approval by the COOMET President.

According to the CIPM MRA D-04 prior to be submitted for the inter-regional review, the CMCs should be reviewed and approved by the RMO. COOMET has established the process for the intra-RMO review. This process follows the CIPM MRA-D-04 and assures that the CMCs submitted for the inter-regional review have sufficient technical support. The Technical Committees form groups of technical experts for the review of the comparison's results and CMCs-data.

Starting in 2002, the COOMET Quality Forum directed the CIPM MRA realization. The evaluation of the Quality Management System in COOMET NMIs is carried out during the conduction of peer reviews by COOMET auditors and technical experts once every 5 years and is coordinated by the Technical Committee of COOMET Quality Forum (TC QF). The peer reviews are carried out in accordance with the RMO COOMET Recommendations.

The TC QF is conducting monitoring of Quality Management Systems of NMIs of Member Countries on the basis of cross analysis of annual reports, directed to the Secretariat of TC QF. Currently 22 NMIs from 18 COOMET Member Countries are cooperating within the Quality Forum.

\section{INVOLVING NEW PARTIES IN THE CIPM MRA}

Providing for the traceability in the COOMET region has required great attention and support for countries of Central Asia and the Caucasus Region in the development of national metrology infrastructures, harmonization with international requirements, improving the national standards of these countries, and preparing these NMIs for signing the CIPM MRA. Countries which are on the way to signing: Azerbaijan, Armenia, Kyrgyzstan, Tajikistan and Uzbekistan. Aiming for stable development and cooperation, in the near future COOMET plans to provide for the preparation of these countries to sign and realize the CIPM MRA, for active participation of their national measurement standards in international comparisons, for the creation of Quality Systems for their NMIs, and for implementing the requirements of ISO/IEC 17025.

In order to support these countries, Subcommittee "Support in Developing Basic Metrological Infrastructures of COOMET Member Countries" was established in 2008 within COOMET TC 4 for "Information and Training." This SC has to solve the following tasks in the countries of the region: assistance in the preparation for signing the CIPM MRA; preparation of the staff for QMS application according to ISO/IEC 17025; assistance in conducting comparisons and preparing CMCs; training for national metrology staff; and the organization of training workshops.

With the financial support within the realized PTBCOOMET technical cooperation project titled, "Support of cooperation between member countries of the Regional Metrology Organization - COOMET," several workshops were organized in 2008 - 2012 by COOMET TC 4 for directors and experts of the NMIs.

For example, Workshop for COOMET NMI's internal auditors (see Figure 2) according to ISO/IEC 17025 was held 7-8 of November 2012 in NISM (Chisinau, Republic of Moldova). Workshop participants: 36 representatives from 12 countries Azerbaijan, Armenia, Belarus, Germany, Georgia, Kazakhstan, Lithuania, Moldova, Russia, Slovakia, Tajikistan, Ukraine. The Workshop consisted of theoretical and practical parts.

Next items were presented and discussed:

- The basics of QMS in NMI;

- COOMET regulations and procedures on the assessment of QMS NMI;

- Requirements according to ISO/IEC 17025.

The "model" internal audit of NISM laboratories was carried out. After "model" internal audit the participants were tested and received the Certificates.

Considering the great importance of the CIPM MRA in broadening the economic, scientific, technical, and international cooperation, as well as eliminating technical barriers to trade, the activity performed in this field will surely result in signing of the Metre Convention by the governments of the above-mentioned countries or acquiring the status of an Associate to the General Conference of Weights and Measures (CGPM) in order to participate in the

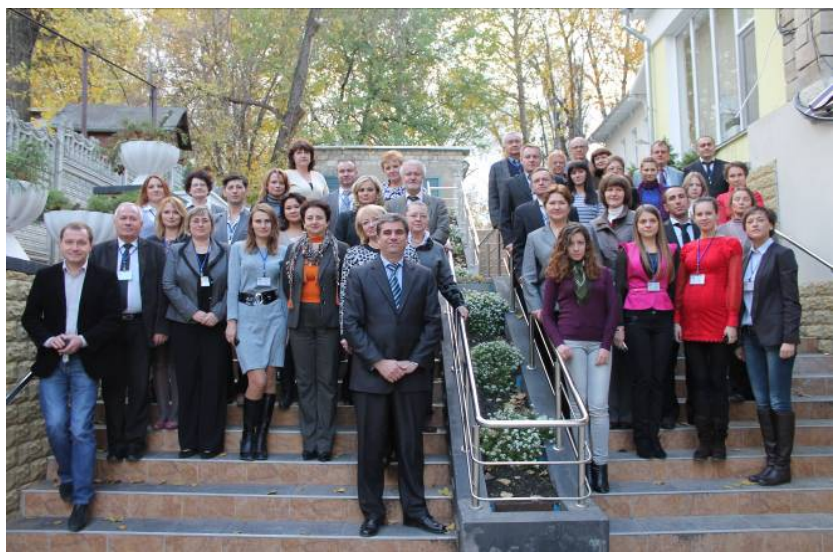

Figure 2. Participants of the workshop in Moldova. 
implementation of the CIPM MRA in the near future.

\section{COOPERATING IN THE FIELD OF LEGAL METROLOGY}

COOMET MoU contains a number of regulations which are absent in the by-law documents of other regional organizations. For example, COOMET activities concern not only scientific but also legal metrology.

Legal metrology is one of the well-developed areas of cooperation in COOMET Member Countries. At the 20th COOMET Committee meeting in 2010 [4], a new structure of TC 2 for Legal Metrology was approved.

The new structure consists of the following subcommittees:

- SC 2.1 Harmonization of Regulations and Norms

- SC 2.2 Technologies of Measuring Devices and Systems in Legal Metrology

- SC 2.3 Competence Assessment of Bodies in Legal Metrology

- SC 2.4 Legal Metrological Control (LMC)

- The tasks of these SCs are the following:

- SC 2.1: Acceptance or adaptation of approved international or regional documents (e.g: VIML, OIML Documents, WELMEC Guides, EC Recommendations).

- SC 2.2: Development of test procedures for measuring instruments (MI), including software and measuring systems, but also data transfer and other future technologies.

- SC 2.3: Development of criteria for the assessment of verification laboratories and other parties.

- SC 2.4: Establishment of projects for the elements of LMC (Surveillance QM, Market Surveillance, Field Surveillance).

The main purpose of the changes in the structure of TC 2 was to improve the efficiency and optimization of the legal metrology activities based on the experience of the International Organization of Legal Metrology (OIML) and other regional legal metrology organizations.

The new structure of TC 2 allows for further expansion of cooperation in the field of legal metrology. The discussion on the new content of work within TC 2 shows that the countryspecific interests should be considered. All TC 2 member states have the same aim, which is to build and enforce an operational, effective system for legal metrology. The new subcommittee structure is open for different realizations and for future changes in the methods for legal metrology. One example is the current low interest in market surveillance of several states, while others use this system more than the preventive verification system. So the question for all is how mutual acceptance can be created in the case of free trade of products, i.e., prepackaged goods or measuring instruments. In this context, the growing importance of conformity assessment was noted.

\section{JOINT RESEARCH IN METROLOGY}

As a result of many years of discussion of the possibility to realize joint research projects and their sources of funding, a Technical Committee for Joint Research in Metrology, TC 5 , was established in 2009. The tasks of TC 5 for the near future are:

- To identify common research areas;
- To determine priority fields in research and development;

- To determine the efficiency of projects for the economy of COOMET member countries; and

- To identify those interested groups that benefit the most from the implementation of the projects.

It should be noted that there are a number of research projects that are currently implemented within COOMET: Earth Rotation Period (ERP) determination on the basis of data from observatories of COOMET countries; Metrology of nanotechnology, Standardization of Eu-152 radionuclide solution; etc.

For example, within ERP COOMET project, in 2010 the observatories in Russia, Ukraine, Uzbekistan, Bulgaria, Poland, and the Czech Republic made routine star and satellite observations and then transmitted the observation data to the ERP processing and calculating centre at VNIIFTRI. An exchange of ERP observing data and calculating results was made between the participating countries and the International and National Centres for ERP determination. The calculations of the pole coordinates and duration of the day by the results of GPS observations at the stations on the territory of Russia were made on a regular basis. The accuracy of ERP determination by means of all the techniques of the country participants was about 0.0002 " and $0.02 \mathrm{~ms}$ with regard to the pole coordinates and to the Universal Time, respectively. These values closely approach the accuracy of products of the International Earth Rotation Service (IERS).

However, the number of these projects is rather small. Therefore, for realization of significant TC 5 tasks, the following project was initiated: COOMET 492/DE/10 "Development of a concept for joint metrology research in COOMET member countries". Within this project the Working Group (WG) prepared the questionnaires for conducting the following:

- State-of-art analysis;

- Research needs of participating countries;

- Structuring and prioritizing of potential research projects;

- Identification of research subjects of common interest (e.g., metrology for energy, for environment, for health, security and safety, etc. - grand challenges in the field of metrology);

- Expected social and economic impact of the research and development outcome.

The meeting of the WG was held in July 2012 in NSC "Institute of Metrology", Ukraine. At this meeting questions connected with the need of joint research in COOMET were considered, common tasks and the scope of the EuropeanAsian Metrology Research Venture (EAMRV) were discussed, as well as the aspired social economic impact, possible styles of cooperation, procedures for determining and application of EAMRV etc. Further, the results from three questionnaires were evaluated by the WG and were sent to the representatives of COOMET member-countries:

- Questionnaire No.1 "NMI's current research-anddevelopment resources, capabilities, capacities and international cooperation"; 
- Questionnaire No.2 "Aspired capacity, capability and quality of the national calibration, measurement and testing infrastructure";

- Questionnaire No.3 "Metrology for the future and demands on joint metrological research".

In order to realize this project, COOMET proceeds from world achievements in the field of metrology related to science, industry and economy of all cooperating countries, and, at the same time, establishes a self-contained metrology research strategy for the European-Asian transition area, including Central Asian and Caucasian regions, tailored to particular economical needs of its Member Countries. The development and implementation of joint projects in
COOMET will contribute to basic science and technology, as well as stimulate innovations to solve metrology problems in COOMET Member Countries.

\section{REFERENCES}

[1] http://www.coomet.net, http://www.coomet.org.

[2] http://www.bipm.org/en/cipm-mra/mra_online.html.

[3] http://www.bipm.org/utils/common/CIPM_ MRA/CIPM MRA-D-04.pdf.

[4] P. Neyezhmakov. "20 years of COOMET: we measure together for a better tomorrow", OIML Bulletin. - July 2011, Vol. LII № 3. - pp. 32-37. 